\title{
Use of morphine sulphate by South African paramedics for prehospital pain management
}

\author{
Craig Vincent-Lambert PhD, Joalda Marthiné de Kock BTech EMC
}

C Vincent-Lambert, JM de Kock. Use of morphine sulphate by South African paramedics for prehospital pain management. Pain Res Manag 2015;20(3):141-144.

BACKGROUND: Evidence in the literature highlights the fact that acute pain in the prehospital setting remains poorly managed. Morphine remains the most commonly used analgesic agent in the South African prehospital emergency care setting. Although guidelines and protocols relating to the dosage and administration of morphine exist, little data are available describing its use by South African paramedics.

OBJECTIVES: To document and describe the way in which morphine is administered by a sample of South African paramedics for the management of acute pain in the prehospital setting.

METHODS: An Internet-based survey was conducted. Sixty South African paramedics responded by completing the online questionnaire documenting and describing their use of morphine for management of acute pain.

RESULTS: Results revealed that participants appeared to be overly cautious of potential adverse effects associated with administration of morphine. Although the majority of participants calculated the dose of morphine to be administered correctly according to the patient's weight, the majority do not appear to be administering this as a bolus; rather, they administer the calculated loading dose in a titrated manner over time. This method may result in a delay and or failure to adequately achieve therapeutic serum levels.

CONCLUSION: Failure to administer an appropriate bolus or 'loading dose' when administering morphine intravenously may result in ineffective and delayed pain management. The authors recommend more clearly defined protocols be developed to guide the use of morphine sulphate by paramedics in the local emergency medical services environment.

\section{L'utilisation de sulfate de morphine par le personnel paramédical sud-africain pour gérer la douleur préhospitalière}

HISTORIQUE : Les publications démontrent que, pendant la période préhospitalière, la douleur aiguë est mal gérée. En Afrique du Sud, la morphine demeure l'analgésique le plus utilisé à la salle d'urgence avant l'hospitalisation. Même s'il existe des directives et des protocoles sur les doses et l'administration de morphine, peu de données en décrivent l'utilisation par le personnel paramédical sud-africain.

OBJECTIFS : Attester et décrire la manière dont la morphine est administrée par un échantillon d'employés paramédicaux sud-africains pour gérer la douleur aiguë préhospitalière.

MÉTHODOLOGIE : Les chercheurs ont sondé 60 employés paramédicaux sud-africains qui ont répondu à un questionnaire virtuel pour attester et décrire leur utilisation de morphine afin de gérer la douleur aiguë.

RÉSULTATS : Les résultats ont révélé que les participants semblaient être trop prudents à l'égard des réactions indésirables potentielles de la morphine. Même si la majorité d'entre eux calculaient correctement la dose de morphine à administrer en fonction du poids, la plupart ne semblaient pas l'administrer sous forme de bolus, mais titraient la dose d'attaque calculée au fil du temps. Cette méthode peut provoquer un délai avant l'atteinte du taux sérique thérapeutique ou même empêcher d'y parvenir.

CONCLUSION : Le défaut d'administrer un bolus suffisant comme dose d'attaque de morphine par voie intraveineuse peut retarder ou empêcher une gestion efficace de la douleur. Les auteurs recommandent la préparation de protocoles plus clairement définis pour orienter l'utilisation de sulfate de morphine par les employés paramédicaux des services médicaux d'urgence locaux.

Key Words: Dose; Management; Morphine; Pain; Paramedic; Prehospital

\begin{abstract}
dministration of analgesia by paramedics can significantly Aimprove patient comfort in the prehospital setting, helping to facilitate immobilization and care on scene, during transport and in the emergency department (ED). Ineffective or delayed administration of analgesia in the field may lead to significant pain in the ED (1). The present study investigated and described the use of morphine sulphate in the South African prehospital setting by paramedics, and compared their practices to existing guidelines and literature.
\end{abstract}

\section{MANAGEMENT OF PAIN IN THE PREHOSPITAL CONTEXT}

Pain is a common experience among the critically ill or injured while being transported (2-6). Factors that may contribute to patient discomfort and pain during prehospital transportation include vibration, thermal changes, uneven road conditions and noise (5). The nature of the prehospital environment may also hamper paramedics' ability to assess pain properly (5). Pain has been described as a 'fifth vital sign' and pain management should be prioritized, after the treatment of lifethreatening injuries (2-7). Despite this, pain in the prehospital emergency setting, as well as in the ED, remains poorly managed (8-14). Reasons for this include practitioners' fears of adverse effects associated with the administration of analgesic agents, unwanted masking of underlying pathology, the 'expectation' of pain being experienced by patients in the emergency setting or the indifference of emergency medical service providers to patients' complaints of pain (4-12).

Failure to provide adequate analgesia is associated with a number of undesirable outcomes, one of which is the potential development of hyperalgesia, an adapted central nervous system condition in which patients experience an abnormally heightened response to future pain stimuli (15-17). Untreated acute pain has also been known to lead to irreversible chronic or neuropathic pain as well as depression, posttraumatic stress disorder and poor compliance with rehabilitation strategies (16-19). In addition to the above, an increase in sympathetic tone is a common result of painful stimuli $(1,20)$. This sympathetic stimulation

Department of Emergency Medical Care and Podiatry, Faculty of Health Sciences, University of Johannesburg, Johannesburg, South Africa Correspondence: Dr Craig Vincent-Lambert, Department of Emergency Medical Care, Faculty of Health Sciences, University of Johannesburg,

Doornfontein Campus, PO Box 17011, Doornfontein 2028, South Africa. Telephone 27-11-559-6257, e-mail clambert@uj.ac.za

OPEN $\bigcirc$ ACCESS

This open-access article is distributed under the terms of the Creative Commons Attribution Non-Commercial License (CC BY-NC) (http:// creativecommons.org/licenses/by-nc/4.0/), which permits reuse, distribution and reproduction of the article, provided that the original work is properly cited and the reuse is restricted to noncommercial purposes. For commercial reuse, contact support@pulsus.com 
TABLE 1

\section{Scenarios in which administration of morphine is considered}

\begin{tabular}{lc}
\hline Complaints & $\begin{array}{c}\text { Participants who indicated they would } \\
\text { administer morphine }(\mathbf{n}=60)\end{array}$ \\
\hline Fractures & $60(100)$ \\
Dislocations & $58(96.7)$ \\
Burns & $57(95.0)$ \\
Chest pain & $54(90.0)$ \\
Severe soft tissue injury & $49(81.7)$ \\
Mild abdominal pain & $3(5.0)$ \\
Moderate abdominal pain & $10(16.7)$ \\
Severe abdominal pain & $34(56.7)$
\end{tabular}

Data presented as $n(\%)$

and excessive stress response leads to an increase in cardiac work and peripheral vascular resistance with the potential for associated cardiac ischemia $(1,13,21)$. Nausea and vomiting are also commonly associated with severe acute pain (20). Pain and the associated adverse effects mentioned above are commonly aggravated during prehospital transport $(1,4)$.

Prehospital analgesia began with the introduction of medicinal brandy and other liquor as a means of pain relief during the 1860s. Prehospital opioids were introduced in the 1970s (2). Opioids have proven to be excellent analgesics for the management of moderate to severe acute pain. Morphine sulphate is currently the most widely known and used opioid, and has become the standard against which all others are measured $(9,10,22)$. It is a narcotic analgesic that binds to opioid receptors in the brain and spinal cord, resulting in a subsequent increase in the pain threshold (16). Morphine sulphate is reliable in its effects and can be administered intravenously, intramuscularly and subcutaneously, with a peak effect occuring between $10 \mathrm{~min}$ and 30 min after administration $(2,9,10)$.

The safety and advantages of morphine sulphate administration have been well documented $(2-15,21)$, resulting in morphine becoming the most commonly used agent for analgesia in the South African prehospital environment.

\section{METHODS}

A nonexperimental, quantitative, prospective descriptive design involving an Internet-based survey was developed for the present study (23). Ethics approval was granted by the University of Johannesburg (Johannesburg, South Africa) Faculty of Health Sciences Ethics Committee. The survey questions were mostly closed ended, with a Likert-type scale limited to 'always', 'sometimes' or 'never', or 'agree/ disagree' options, or a statement was presented with a list of preset options. Free-text comment boxes were provided for participants who wished to elaborate on their selected answers. The survey could only be accessed by means of an invitation e-mail and was open for one month. By the end of the data collection period, 60 responses were received that were complete and suitable for analysis. Simple descriptive analysis was used to evaluate the results. Content analysis was used to analyze the limited qualitative data, which consisted of the comments provided by the participants in the free-text comment boxes, to determine interesting themes and trends linked to the questions.

\section{RESULTS}

Decision making regarding management of pain in the prehospital environment

Participants appeared to be taking several factors into account when making a decision about whether to administer morphine for pain relief. These include: the perceived level of pain being experienced and the patient's desire for pain relief; practitioners' fears of adverse effects; and transportation (mode, time and conditions). Participants indicated that many patients are unable to request analgesia due to decreased level of consciousness or a language barrier; therefore, establishing a pain score is not always possible. In such cases, participants indicated that they rely on the clinical presentation of the patient and vital signs, together with their
TABLE 2

Reasons provided for selecting a lower starting dose

\begin{tabular}{lc}
\hline Reasons & $\begin{array}{c}\text { Responses } \\
\text { ( } \mathbf{n}=9)\end{array}$ \\
\hline Patients sometimes lie about the extent of their pain & $4(44.4)$ \\
I am wary of respiratory depression & $5(55.6)$ \\
I am wary of nausea and vomiting & $7(77.8)$ \\
I am wary of hypotension & $6(66.7)$ \\
I don't want to blunt diagnostic procedure in the ED & $4(44.4)$ \\
This dose is sufficient to dull the pain to a tolerable level & $4(44.4)$ \\
\hline
\end{tabular}

Data presented as $n$ (\%). ED Emergency department

clinical experience, to make a decision regarding the need for analgesia. Interestingly, multiple participants indicated they do not make use of a formal pain scoring system to guide their administration of analgesia.

Injuries commonly resulting in morphine administration

Participants were provided with a list of clinical complaints that are commonly associated with significant pain and were asked to indicate whether they would administer morphine. Table 1 summarizes the responses.

The following themes emerged from analysis of the participants' written comments in relation to the above question:

- Participants will administer morphine only if there were no contraindications present, with many indicating significant concerns about "risks of adverse effects".

- Many participants were reluctant to administer morphine to patients with undiagnosed abdominal pain.

- Administration of morphine for chest pain of cardiac origin would only be considered if the administration of nitrates had no effect.

Morphine dose and administration

The question posed was: "In a hemodynamically stable patient with acute severe pain, I will administer an initial bolus dose of:"

Two options were provided, in which participants had to select from either a low-dose regimen of $0.05 \mathrm{mg} / \mathrm{kg}$ followed by $0.025 \mathrm{mg} / \mathrm{kg}$ after $5 \mathrm{~min}$, or a higher dose of $0.1 \mathrm{mg} / \mathrm{kg}$ followed by $0.05 \mathrm{mg} / \mathrm{kg}$ after $5 \mathrm{~min}$.

Analysis of the responses showed that nine of 60 (15.0\%) participants preferred the lower-dose option. Participants who selected this option were further prompted to indicate why they selected the lowerdose option. Table 2 summarizes their responses.

The remaining $85 \%$ of participants, who selected the higher dose, were also prompted to indicate why they selected the higher-dose option. The reasons provided are summarized in Table 3 .

Four interesting themes emerged from analysis of the participants' responses and written comments in relation to their administration of morphine:

- Multiple participants believed that the risk of 'adverse effects' is dependent on the rate of administration and not the dose.

- Participants who selected the higher-dose option indicated they believed that a patients' pain and suffering needs to be relieved, not simply palliated, and that the higher dose is, therefore, more appropriate.

- Although the majority of participants calculated the dose of morphine to be administered correctly according to the patient's weight, the majority (50 of 60 [83\%]) do not appear to be administering this as a bolus; rather, they indicate they administered the calculated loading dose in a titrating manner over time. This method may result in a delay and/or failure to adequately achieve therapeutic serum levels.

- The majority of participants appeared to be highly cautious about potentially overdosing their patients, with 27 of 60 (45.0\%) indicating they would 'never' exceed an initial bolus dose of $5 \mathrm{mg}$ of morphine. The remaining 32 of 60 (53.3\%) said they would never give $>10 \mathrm{mg}$ of morphine even if the patient's weight allowed it. Reasons cited for not giving larger bolus doses centred on concerns about potential 'adverse effects' associated with morphine administration. 
TABLE 3

Reasons provided for selecting a higher starting dose

\begin{tabular}{lc}
\hline Options & Responses $(\mathbf{n}=\mathbf{5 1})$ \\
\hline $\begin{array}{l}\text { Patients will not experience adverse effects if there } \\
\text { is a definite pain response present }\end{array}$ & $22(43.1)$ \\
$\begin{array}{l}\text { Adverse effects are dependent on the rate at which } \\
\text { the analgesic is administered rather than the dose }\end{array}$ & $34(66.7)$ \\
Pain needs to be alleviated and not just blunted & $27(52.9)$ \\
Pain may be detrimental to patient outcome & $22(43.1)$ \\
\hline
\end{tabular}

Data presented as $n$ (\%)

Perceived end points of prehospital analgesia

Another question posed to participants was "What are your end points in determining therapeutic effect of analgesia?". Table 4 summarizes the responses to this question.

The following emerged from the participants' written comments. The first was that gauging pain relief is largely dependent on the patients' level of consciousness and their ability to express relief from the pain. In cases in which the patient was not able to do so, participants use the patient's vital signs and general appearance, together with their own discretion and experience, to determine whether adequate analgesia was being provided.

\section{DISCUSSION}

Pain needs to be alleviated and not just 'blunted' due to the potentially detrimental effects of pain on patient outcome (16-19,22). Morphine has been demonstrated to be an effective analgesic agent and continues to be routinely administered for the management of acute pain in the South African prehospital emergency care environment. Although South African paramedics appear to be considering a number of factors before making a decision on whether morphine administration is required, formal assessment of the level of pain using a pain scoring system is not always occurring. Although it is acknowledged that calculation of a formal pain score is sometimes difficult in the prehospital environment, it nonetheless remains a useful tool to assess treatment efficacy $(5,24,25)$. Similar to findings in other studies, participants in the present study appeared to be overly cautious and fearful of the risk of adverse effects associated with morphine administration $(4,26)$. Reasons for this remain unclear because morphine has been proven to be an excellent analgesic and safe agent for the management of moderate to severe pain $(9,10)$. In addition, the continuous monitoring devices available to paramedics in the South African prehospital setting can assist in early identification and management of potential adverse effects associated with morphine administration should they occur (26).

Concerning the dosage and administration of morphine, it was found that the majority of participants in the present study correctly calculated the initial dose of morphine according to the patient's weight $(0.1 \mathrm{mg} / \mathrm{kg})$. However, it appears that many are failing to administer this dose as a bolus; rather, they are administering the calculated $0.1 \mathrm{mg} / \mathrm{kg}$ loading dose in a titrated manner. This method may result in a delay and/or failure to adequately achieve therapeutic serum levels and associated analgesia. In addition, almost one-half of the participants indicated they would not consider exceeding an initial bolus dose of $5 \mathrm{mg}$ even if the patient's weight allowed for it. Reasons cited for not giving a larger bolus dose centred around concerns about potential adverse effects. According to the literature, such concerns are often overstated because adverse effects, such as hypotension, are not as prevalent in the setting of a severe pain stimulus $(4,26)$. A possible reason for this 'underdosing' may also be due to the fact that there is no mention of a standard starting or 'loading' dose in the South African paramedic practice protocols, which are published by the Health Professions Council of South Africa (HPCSA). The local protocol does, however, mention that the administration of morphine should be titrated to effect, meaning that the minimal effective dosage should be administered to obtain the desired response (27). Failure of

\section{TABLE 4}

Participants' perceived end points of analgesia

\begin{tabular}{lc}
\hline Options & Responses $(\mathbf{n}=60)$ \\
\hline The patient verbalizes relief of pain & $53(88.3)$ \\
The heart rate decreases & $34(56.7)$ \\
The blood pressure decreases & $16(26.7)$ \\
I do a subsequent pain score assessment and & $52(86.7)$ \\
determine if it has decreased & $9(15.0)$ \\
There are adverse effects present such as \\
$\begin{array}{l}\text { hypotension, bradycardia, respiratory } \\
\text { depression, a decreased level of consciousness } \\
\text { and/or nausea }\end{array}$ \\
\hline
\end{tabular}

the HPCSA guidelines to explicitly advocate a minimum weight based loading dose may, therefore, be contributing to the reported underdosing. It is the authors' understanding that 'titrate to effect' does not mean that the initial loading dose should be administered in increments. Rather, 'titrate to effect' refers to the administration of subsequent doses that are given after the initial loading dose to ensure that the analgesic effect, once achieved, is properly maintained (28). Interestingly, Bijur et al (28) found that even when bolus dosages of $0.1 \mathrm{mg} / \mathrm{kg}$ morphine were administered to patients in acute severe pain, $95 \%$ of the patients still reported $<50 \%$ decrease in pain after $30 \mathrm{~min}$. This brings into question whether the currently recommended bolus dose of $0.1 \mathrm{mg} / \mathrm{kg}$ is, in fact, sufficient to adequately manage severe pain in the acute emergency setting (28).

\section{Limitations of the study}

There were several limitations and challenges with regard to the design of the present study. The number of survey invitations that were sent was limited to the number of e-mail addresses that could be obtained by the researchers. Although the response rate of 38\% (60 of 156) is considered to be acceptable for surveys of this nature, in this instance, we do not know exactly how many registered advanced life support practitioners are actually actively practicing in South Africa. This is due to the fact that many no longer practice or have left the country, yet they retain their registration with the HPCSA. For these reasons, it is possible that the findings may not be reflective of all advanced life support practices in all regions of the country. A follow-up study including a larger sample with proportional representation from each region of the country that examines additional demographic data is, therefore, recommended.

\section{CONCLUSION}

Failure to administer an appropriate loading dose when administering morphine intravenously may result in ineffective or delayed pain management. Taking into consideration the findings of the present study, we recommend a more clearly defined local protocol be developed because the phrase 'titrate to effect' appears to have been misinterpreted by a number of the participants. Revised paramedic protocols need to explicitly advocate the administration of a weight-based bolus dose followed by additional doses that can be titrated to effect to maintain therapeutic serum levels.

DISCLOSURES: No conflicts of interest exist in relation to the study or this article.

ETHICS CONSIDERATIONS: Ethics approval for the study was granted by the University of Johannesburg's Faculty of Health Sciences Academic Ethics Committee.

AUTHOR CONTRIBUTIONS: Craig Vincent-Lambert was the supervisor and project leader. Craig Vincent-Lambert wrote this manuscript. Marthiné de Kock gathered and assisted in analyzing the raw data, wrote and submitted the original research report on which this article is based. 


\section{REFERENCES}

1. Marcotte A, Metz M. Pain management in the pre-hospital setting. J Emerg Nurs 2004;30:403.

2. Hennes H, Kim MK. Pre-hospital pain management: Current status and future direction. Clin Pediatr Emerg Med 2006;7:25-30.

3. White LJ, Cooper JD, Chambers RM, Gradisek RE. Pre-hospital use of analgesia for suspected extremity fractures. Prehosp Emerg Care 2000;4:205-8.

4. McEachin CC, McDermott JT, Swor R. Few emergency medical services patients with lower-extremity fractures receive pre-hospital analgesia. Prehosp Emerg Care 2002;6:406-10.

5. Fast M, Newton S, Rochester M. Assessment of pain in the transport environment: A review of the literature. J Emerg Nurs 2008;34:301-4.

6. Turturro MA. Pain, priorities, and pre-hospital care. Prehosp Emerg Care 2002;6:486-8.

7. Decosterd I, Hugli $O$, Tamchès E, et al. Oligoanalgesia in the emergency department: Short-term beneficial effects of an education program on acute pain. Ann Emerg Med 2007;50:462-71.

8. Hennes H, Kim MK, Pirrallo RG. Pre-hospital pain management: A comparison of providers' perspectives and practices. Prehosp Emerg Care 2005;9:32-40.

9. Ricard-Hibon A, Chollet C, Saada S, Loridant B, Marty J. A quality control program for acute pain management in out-ofhospital critical care medicine. Ann Emerg Med 1999;34:738-744.

10. Telio C, Carli P. Pre-hospital and emergency room pain management for the adult trauma patient. Tech Reg Anesth Pain Manag 2002;6:2-9.

11. Marco CA, Marco AP, Buderer NF, Jones JM. Pain perception among emergency department patients with headache: Responses to standardized painful stimuli. J Emerg Med 2007;32:1-6.

12. Bounes V, Barniol C, Minville V, Houze-Cerfon C, Ducassé J. Predictors of pain relief and adverse events in patients receiving opioids in a pre-hospital setting. Am J Emerg Med 2011;129:512-7.

13. Costantini M, Viterbori P, Flego G. Prevalence of pain in Italian hospitals: Results of a regional cross-sectional survey. J Pain Symptom Manag 2002;23:221.

14. Bakkelund KE, Sundland E, Moen S, Vangberg G, Mellesmo S, Klepstad P. Undertreatment of pain in the prehospital setting:
A comparison between trauma patients and patients with chest pain. Eur J Emerg Med 2013;20:428-30.

15. Ricard-Hibon A, Belpomme V, Chollet C, et al. Compliance with a morphine protocol and effect on pain relief in out-of-hospital patients. J Emerg Med 2008;34:305-10.

16. Jones JB. Pathophysiology of acute pain: Implications for clinical management. Emerg Med 2001;13:288-92.

17. Tracey I. Imaging pain. Br J Anaesth 2008;101:32-9.

18. Giboney G. The medical necessity of adequate pain management. Pain Forum 1996;5:227-33.

19. Pointer JE, Harlan K. Impact of liberalization of protocols for the use of morphine sulphate in an urban emergency medical services system. Prehosp Emerg Care 2005;9: 377-81.

20. Huang N, Cunningham F, Laurito CE, Chen C. Can we do better with postoperative pain management? Pain 2004;107:1-4.

21. Shavit Y, Beilint B. Morphine: A double-edged sword. Pain Forum 1996;5:237-9.

22. Bounes V, Charpentier S, Houze-Cerfon C, Bellard C, Ducassé JL. Is there an ideal morphine dose for pre-hospital treatment of severe acute pain? A randomized, double-blind comparison of 2 doses. Am J Emerg Med 2008;26:148-54.

23. Samuels ML, WitmerJA. Statistics for the Life Sciences, 3rd edn. New Jersey: Pearsons Education, Inc, 2003.

24. Herr K, Bjoro K, Decker S. Tools for assessment of pain in nonverbal older adults with dementia: A state-of-the-science review. J Pain Symptom Manag 2006;31:170-92.

25. Breivik H, Borchgrevink PC, Allen SM, et al. Assessment of pain. Br J Anaesth 2008;101;17-24.

26. Jones GE, Machen I. Pre-hospital pain management: The paramedics' perspective. Accid Emerg Nurs 2003;11:166272.

27. Beck RJ, Rahm SJ, Pollak AN, eds. Intermediate Emergency Care and Transportation of the Sick and Injured. Massachusetts: Jones and Bartlett, 2005.

28. Bijur PE, Kenny MK, Gallaghar EJ. Intravenous morphine at $0.1 \mathrm{mg} / \mathrm{kg}$ is not effective for controlling severe acute pain in the majority of patients. Ann Emerg Med 2005;46:362-7. 


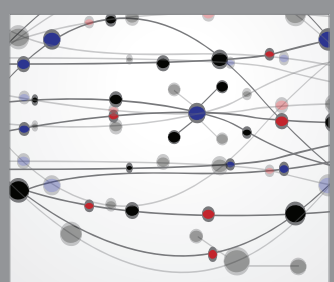

The Scientific World Journal
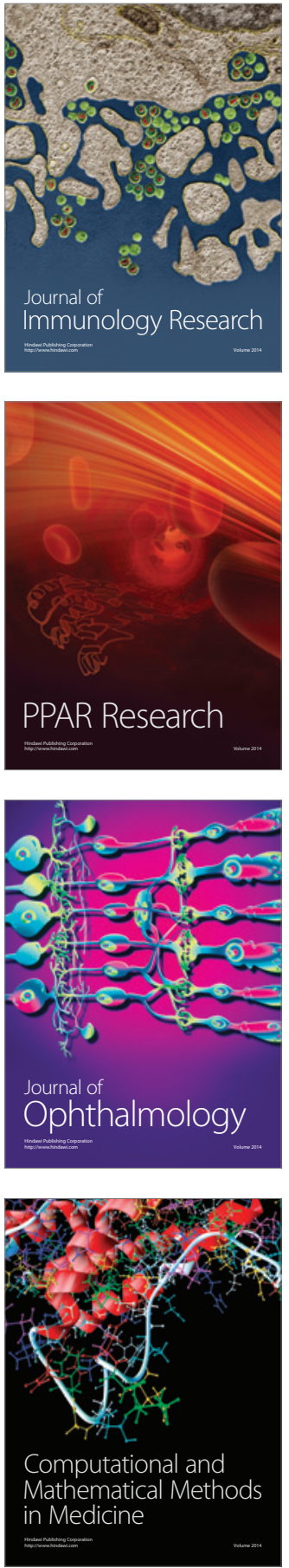

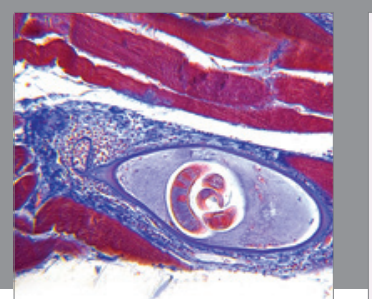

Gastroenterology Research and Practice

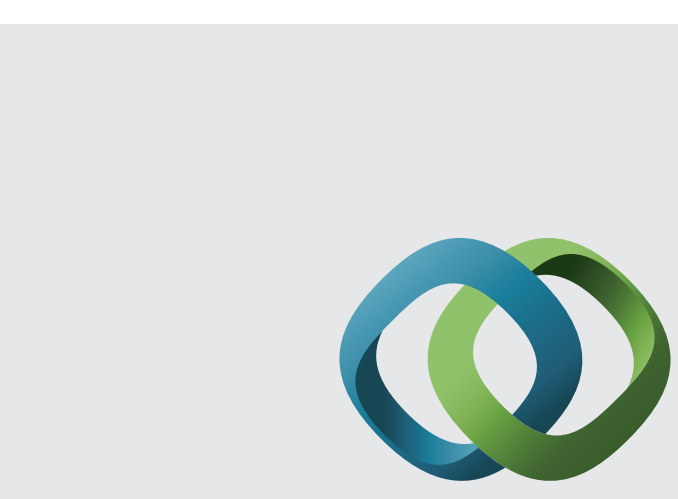

\section{Hindawi}

Submit your manuscripts at

http://www.hindawi.com
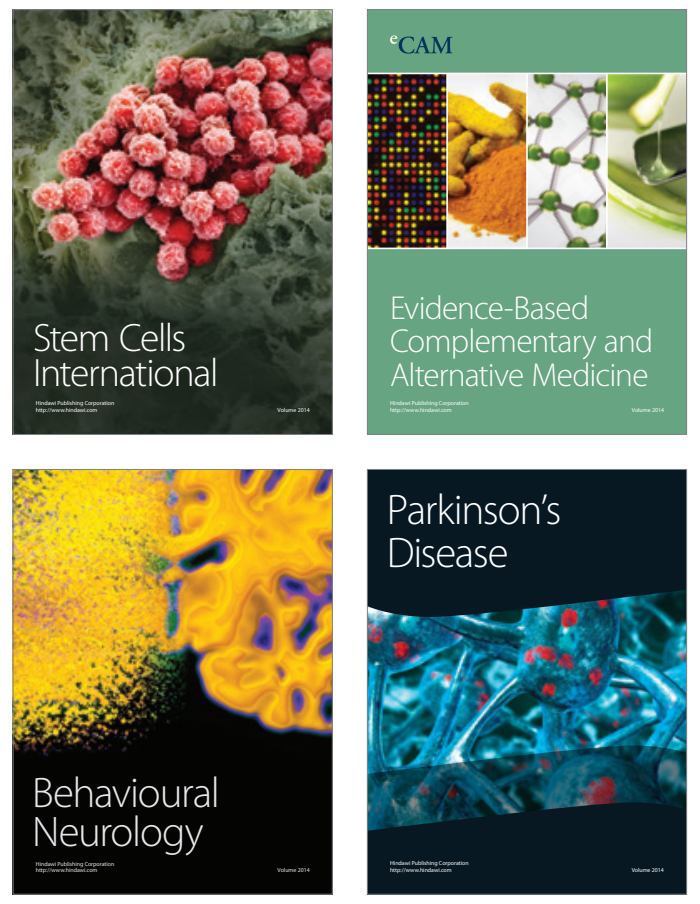
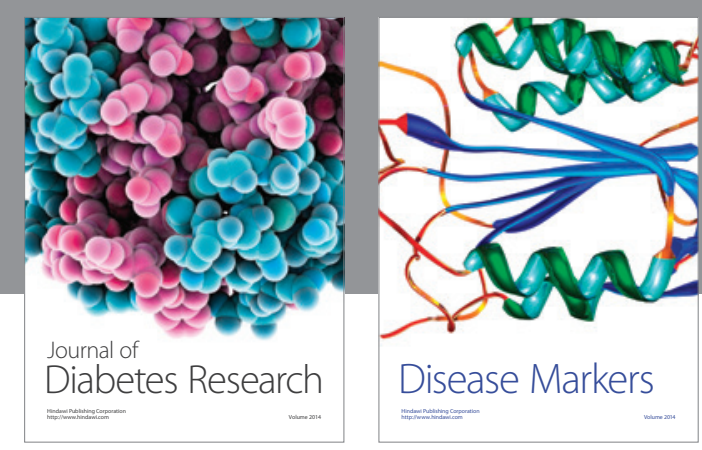

Disease Markers
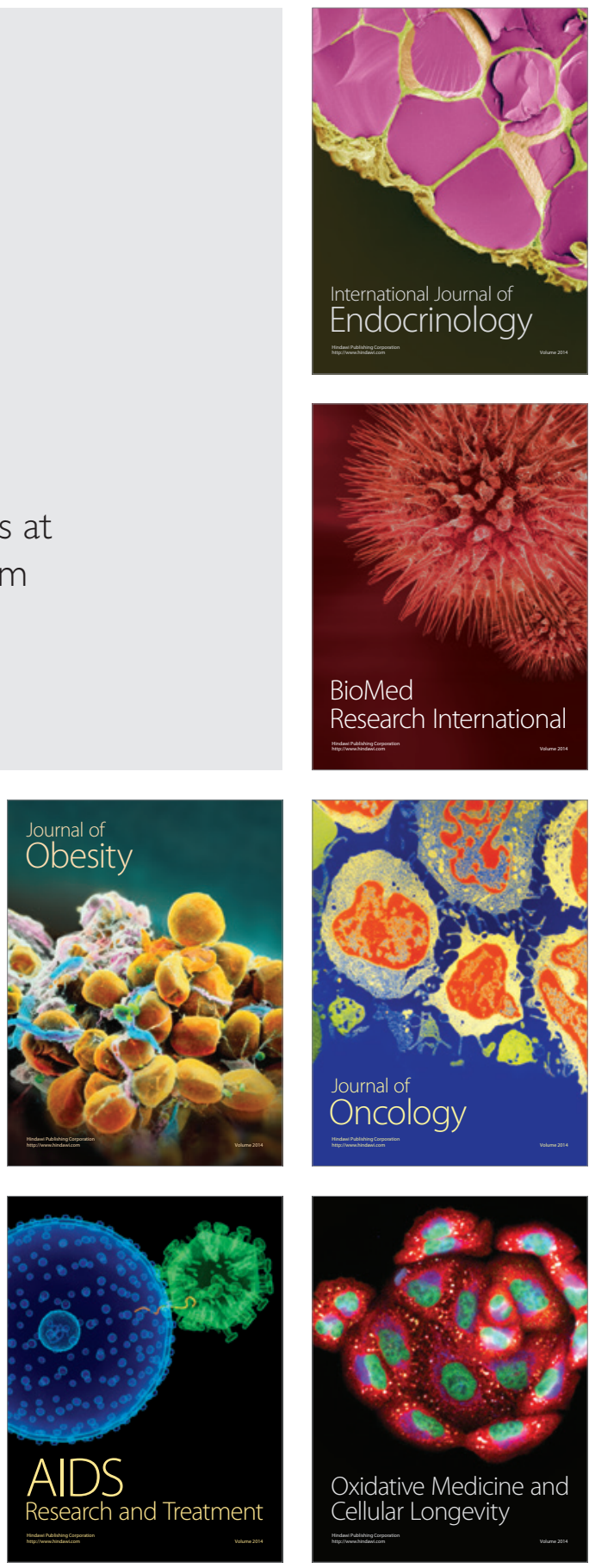